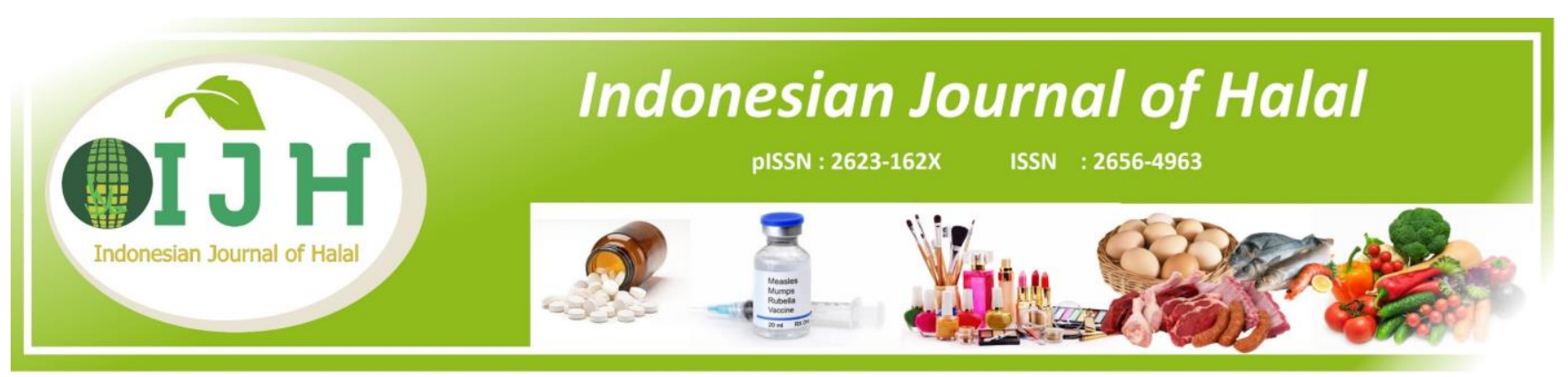

\title{
Peranan Kaedah-Kaedah Fundamental Kebahasaan Dalam Penetapan Produk Halal
}

\author{
Warto $^{1 *)}$, Ahmad Rofiq ${ }^{2)}$, Mashudi ${ }^{3)}$ \\ ${ }^{1)}$ Program S3 Manajemen Halal, UIN Walisongo Semarang \\ ${ }^{2)}$ Direktur LPPOM, MUI Jawa Tengah Semarang \\ ${ }^{3)}$ Lektor Kepala Hukum Islam. UIN Walisongo Semarang \\ ${ }^{*}$ Penulis korespondensi: wartomesy@gmail.com
}

\begin{abstract}
Abstrak
Dalam proses penetapan hukum, seorang mujtahid membutuhkan perangkat istinbath, yaitu berupa kaedah-kaedah ushul fiqh sebagai pijakan metodologis. Kaedah-kaedah ini dirancang oleh para ulama ushul fiqh agar dalam menentukan hukum seorang mujtahid memiliki acuan baku sesuai dengan maqashid syariah. Dengan menggunakan metode penelitian kualitatif deskriftif kaedah istinbath hukum ini yang akan dikaji dalam paper ini. Fokus pembahasan dalam studi ini kaedah fundamental kebahasaan. Pemilihan pokok bahasan ini didasarkan pada kebutuhan istinbath hukum, bahwa kaedahkaedah ini memiliki peranan sangat penting dalam melahirkan produk hukum, agar hukum yang dihasilkan benar-benar aplikatif dan relevan.
\end{abstract}

Kata kunci: kaedah, ushuliyah, istinbath, ijtihad

\begin{abstract}
Role of The Fundamental Habits of Rules In Determining Halal Products. In the process of determining the law, a mujtahid needs an istinbath device, which is in the form of ushul fiqh methods as a methodological basis. These methods were designed by the ulema of the ushul fiqh so that in determining the law a mujtahid has a standard reference in accordance with maqashid sharia. By using descriptive qualitative research methods, the istinbath law method will be reviewed in this paper. The focus of the discussion in this study is fundamental to language. The choice of this subject is based on the need for legal istinbath, that these methods have a very important role in giving birth to legal products, so that the laws produced are truly applicable and relevant.
\end{abstract}

Keywords: kaedah, ushuliyah, istinbath, ijtihad

\section{PENDAHULUAN}

Perubahan merupakan sunnah kehidupan. Seiring perubahan itu problematika kehidupan juga terus berkembang dari waktu ke waktu, dari satu tempat ke tempat lain, dari satu generasi ke generasi lain, hingga semakin kompleks dan sulit. Diantara persoalan umat islam saat adalah persoalan halal-haram, baik itu terkait dengan barang-barang konsumsi seperti; makanan, minuman dan obat-obatan, maupun barang-barang guna pakai; semisal kosmetika, perlengkapan kebersihan dan barang lainnya. Semua itu memerlukan solusi. Solusi memerlukan perangakat dan wasilah. Diantara wasilahnya adalah istinbath hukum. Dalam istinbath diperlukan perangkat-perangkat. Diantara perangkat itu adalah ilmu ushul fiqh.

Perluasan wilayah, perbedaan bahasa dan kompleksitas persoalan yang terus berkembang menjadi kendala tersendiri dalam upaya mengaplikasikan teks-teks agama dalam kehidupan. Maka diperlukan pedoman baku dalam menerjemahkan teks-teks agama dalam kehidupan masyarakat muslim. Untuk menjembatani 
hal ini para ulama telah menyusun aturan-aturan baku untuk memahami teks-teks agama tersebut, berupa kaedah-kaedah fundamental kebahasaan/al-Qawaid alUshuliyah al-Lughawiyah. Salah satu upaya untuk memahami unsur kebahasaan pada pesan sang Khaliq yang tertuang dalam al-Quran dan as-Sunnah. Para ulama membuat aturan ini agar ketika meng-istinbath hukum umat tidak menyimpang dari kaedah-kaedah bahasa yang benar. Cakupan wilayah islam yang merambah negara-negara non arab, menjadi problematika tersendiri dalam memahami naskahnaskah agama yang tertuang dalam bahasa Arab. Perbedaan bahasa inilah yang menuntut dibuatnya aturan dan kaedah kebahasaan yang baku agar dalam meng-istinbath hukum tidak keluar dari maksud dan tujuan agama. Dengan dibuatnya aturan dan kaedah bahasa akan lebih memudahkan umat dalam memperoleh solusi atas persoalan yang muncul dan dihadapi secara tepat.

Bahasa Arab merupakan simbol bagi al-Quran dan sunnah, karena al-Quran diturunkan menggunakan bahasa Arab. Demikan halnya Sunnah Qauliyah pun datang dengan menggunakan bahasa Arab. Untuk memahami keduanya dibutuhkan pengetahuan bagaimana cara orang Arab memahami pesan-pesan dalam bahasa mereka. Maka diantara bagian dari ushul fiqh terdapat pembahasan mengenai cara memahami ungkapan atau pelafalan, sehingga diperoleh pemahaman makna yang tepat. Pembahasan tersebut mencakup makna secara umum atau khusus, mutlak atau terbatas, tunggal atau global, tekstual atau maknawi, hakiki atau kiasan. Itu semua terangkum dalam konvensi para pakar bahasa Arab, dimana alQuran diturunkan dengan bahasa mereka dan nabi berbicara menggunakannya. ('Iyadh bin Namy AsSilmy, 2005)

\section{HASIL DAN PEMBAHASAN}

\section{Al-Qawaid al-Ushuliyah Al-Lughawiyah}

Bagi orang Arab tidak banyak kesulitan memahami makna-makna dan pesan-pesan al-Quran dan sunnah, karena keduanya menggunakan bahasa mereka. Namun bagi orang-orang non Arab tidak mudah memahami keduanya, tanpa ada upaya untuk mendalami unsurunsur kebahasaan secara baik dan benar. Oleh karena itu para ulama telah membuat kaedah-kaedah kebahasaan yang berkaitan langsung dengan kedua sumber hukum tersebut.

Pokok-pokok kaedah-kaedah fundamental kebahasaan meliputi pembahasan makna secara; hakiki (haqiqah) ataukah kiasan (majaz), tekstual (manthuq) ataukah maknawi (mafhum), perintah (amar) ataukah larangan (nahi), umum ataukah khusus, mutlak (muthlaq) ataukah terbatas (muqayyad), global (mujmal) ataukah jelas (mubayyan), dan tersurat (zhahir) ataukah tersirat (muawwal).
2. Kaedah-Kaedah Kebahasaan dalam Halal-haram

Di dalam kaedah ushul fiqh dikenal istilah amm dan khas. Amm artinya umum, yaitu ucapan atau kata yang mencakup keseluruhan makna di dalamnya tanpa batas. Dengan pengertian ini, kata yang menggunakan hitungan bukanlah termasuk dalam kategori umum, karena telah dibatasi dengan jumlah, meskipun jumlahnya sangat banyak. Kalimat yang memiliki makna umum termasuk dalam kategori zhanny, selama belum ada takhshis (pengkhususan) (Muhammad Hasan Hito, 2005).

Untuk mengenali kata atau ucapan yang bermakna umum, ada beberapa tanda yang bisa dikenali, di antaranya;

a. Biasanya menggunakan kata

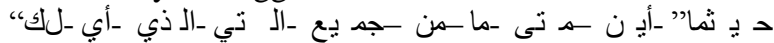

b. Kata yang digunakan itu di "ta'rif" dengan menggunakan "J" baik kata itu berbentuk tunggal atau jamak, maka ia termasuk umum.

c. Kata yang digunakan itu di-ta'rif dengan cara diidhafah-kan, atau berupa kata majmuk.

d. Kata yang dipakai berupa isim nakirah yang didahului dengan "nafi" dan "syarat".

Diantara kaedah fundamental tentang makna "umum" adalah "Apa saja yang bisa dikecualikan adalah umum"

Khas (khusus) adalah kata yang memiliki makna yang terbatas. Sedangkan takhshish adalah mengeluarkan beberapa makna yang terkandung dalam kalimat yang umum.

\section{Kaedah Bahasa Dalam Ayat Halal-Haram}

Allah SWT berfirman, "Diharamkan bagi kalian (memakan) bangkai, darah, daging babi, (daging hewan) yang disembelih atas nama selain Allah, yang tercekik, yang dipukul, yang jatuh, yang ditanduk, dan yang diterkam binatang buas, kecuali yang sempat kamu menyembelihnya, dan (diharamkan bagimu) yang disembelih untuk berhala. Dan (diharamkan juga) mengundi nasib dengan anak panah, (mengundi nasib dengan anak panah itu) adalah kefasikan. (QS. 5: alMaidah; 3).

Sesuai dengan kaedah kebahasaan di dalam ayat di atas terdapat kata-kata yang maknanya masih umum. Allah berfirman, "Diharamkan bagimu (memakan) bangkai" (al-Maitah). Diantara yang diharamkan oleh Allah sesuai dengan ayat di atas adalah bangkai

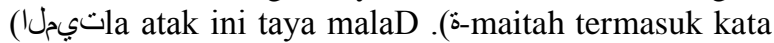
yang umum, karena menggunaka "ل" at-ta'rif. Dengan demikian, sesuai arti ayat di atas semua jenis bangkai itu hukumnya haram.

Bangkai (al-maitah) dalam definisi para ulama, sebagaimana yang dikatakan Abdurrahman Bin Nashir bin Abdullah as-Sa'dy adalah hewan yang mati tanpa proses penyembelihan yang sesuai dengaan syariat. (Abdurrahman Bin Nashir bin Abdullah as-Sa'dy, 2000). Di dalam ayat tersebut juga dijelaskan bentukbentuk bangkai, yaitu "yang tercekik, yang dipukul, 
yang jatuh, yang ditanduk, dan yang diterkam binatang buas, kecuali yang sempat kamu menyembelihnya, dan (diharamkan bagimu) yang disembelih untuk berhala". Semua jenis bangkai ini adalah haram.

Kata al-maitah pada ayat di atas berlaku umum, mencakup semua jenis hewan yang kematiannya tanpa melalui proses penyembelihan secara syar'i, baik itu hewan yang dimakan dagingnya maupun hewan yang tidak biasa dimakan dagingnya.

Dalam kaedah ushul terkait amm-khas, terdapat pula kaedah, bahwa setiap kata umum bisa ditakhshish. Ini juga berlaku pada ayat di atas. Kata almaitah yang memiliki makna umum kemudian ditakhshish dengan hadits nabi yang datang kemudian. Dari Ibnu Umar RA, berkata, "Rasulullah SAW bersabda, "Telah dihalalkan bagi kita dua bangkai dan dua darah, adapun dua bangkai itu adalah ikan dan belalang...” (HR. Ahmad, al-Baihaqy, asy-Syafi'i dan ad-Daruquthny). Dengan demikian makna ayat di atas kemudian terbatasi oleh keterangan hadits sehingga tidak semua bangkai itu haram.

Makna haram sendiri juga memiliki keumuman makna, apakah yang dimaksud haram dalam ayat itu haram secara mutlak; baik haram memakannya atau memanfaatkan dan menggunakannya, atau bahkan haram menjualnya dan haram mengambil harganya. Inilah yang kemudian dipahami sebagian sahabat nabi, dengan memahami bahwa keharaman bangkai tersebut secara mutlak. Hingga ketika ada peristiwa nabi menjumpai kambing mati dan para sahabat tidak mau memanfaatkannya. Dari ibnu Abbas RA, berkata, "Telah disedekahkan seekor kambing kepada sahaya Maimunah. Tiba-tiba kambing itu mati. Kebetulan Rasulullah SAW lewat dan bersabda, "Tidakkah kalian mengambil kulitnya, lalu kalian mensamaknya, dan kalian memanfaatkannya?" Mereka menjawab, "Sesungguhnya ini adalah bangkai?" Nabi SAW bersabda, "Yang diharamkan adalah memakannya saja." (HR. Jama'ah kecuali Ibnu Majah). Hadits ini datang memberikan penjelasan bahwa keharaman bangkai yang dimaksud dalam ayat di atas hanya apabila bangkai itu dikonsumsi. Kulit bangkai, bulu, tulang, dan giginya masih boleh dimanfaatkan sebagai perabot atau peralatan. Ini pula yang dijelaskan dalam hadits yang diriwayatkan oleh Ibnu Abbas Ra. Dari Ibnu Abbas RA, ia membaca ayat ini, "Katakanlah: "Tiadalah aku peroleh dalam wahyu yang diwahyukan kepadaku, sesuatu yang diharamkan bagi orang yang hendak memakannya, kecuali kalau makanan itu bangkai..." (Riwayat Ibnu Mundzir dan Ibnu Hatim). Ibnu Abbas mengatakan, "Sesungguhnya yang diharamkan dari bangkai itu adalah memakannya, yaitu daging, adapun kulit, gigi, tulang, rambut, bulu adalah halal.( Abdurrahman bin Abu Bakar as-Suyuthi, 2003). Dalam kaedah ushul fiqh, jenis takhshish semacam ini dikenal dengan istilah takhshish munfashil. Yaitu takhshish yang penjelasannya terpisah.

Berkaitan dengan makna "bangkai" dalam ayat adalah termasuk bangkai ikan dan belalang. Secara khusus nabi mengecualikan kedua bangkai ini. Sebagaimana dalam hadits nabi saat ditanya sahabat soal air laut. Beliau menjelaskan bahwa air laut itu suci dan halal bangkainya. Diriwayatkan dari Abi Hurairah, RA, berkata, Nabi SAW, ditanya tentang air laut, apakah kita boleh menggunakannya untuk berwudhu? Maka beliau menjawab, "Air laut itu suci mensucikan dan halal bangkainya". (Abu Abdillah al-Hakim, 2002). Pengertian halal bangkainya dalam hadits juga bisa menimbulkan kesalahfahaman. Apakah semua bangkai yang ada di laut termasuk hewan amfibi yang hidup di dua alam, ataukah hewan yang hanya bisa hidup di air. Atau bagaimana dengan hewan darat yang mati di air?

Para ulama berbeda pendapat mengenai hewan yang hidup di dua alam, yaitu di darat dan air. Ulama Malikiah berpendapat bahwa hewan barmaiyah disamakan dengan hewan darat. Tidak boleh di makan kecuali disembelih. Menurut Imam Ahmad bin Hanbal bahwa semua hewan laut hukumnya halal selain katak dan buaya. (Muhammad bin Abdurrahman bin Abdurrahim al-Mubarakfury, 1424). Sedangkan anjing laut harus disembelih. al-Laits bin Sa'd pernah ditanya mengenai hewan laut, ia menjawab bahwa manusia laut (duyung) dan Babi laut tidak boleh dimakan. (alHusain bin Mas'ud al-Baghawi, 1983 ). Imam Abu Hanifah berpendapat bahwa semua hewan laut selain ikan hukumnya haram. (al-Husain Bin Mas'ud alBaghawi, 1983). Menurut ulama Syafi'iyah, hewan laut yang ada padanannya di darat, jika padannya halal, maka hukumnya halal, jika padanannya haram maka hukumnya haram. (Muhammad bin Abdurrahman bin Abdurrahim al-Mubarakfury, 1424). Sedangkan untuk hewan darat yang mati di dalam air, Syeikh Muhammad bin Ismail al-Amir dalam kitab "As-Subul" mengatakan bahwa yang dimaksud "maitah" dalam hadits adalah hewan yang mati di laut dan hidup di laut, yaitu hewan yang tidak bisa hidup kecuali di air, bukan hewan darat yang mati di air. (Muhammad bin Abdurrahman bin Abdurrahim al-Mubarakfury, 1424).

Demikian pula dengan kata "ad-dam" termasuk dalam kategori umum. Sesuai dengan maknanya menunjukkan bahwa semua jenis darah adalah haram. "ل" ta'rif juga memiliki makna "istighraq" yang artinya mencakup keseluruhan. Sehingga maknanya seluruh jenis darah adalah haram. Hal ini ternyata menimbulkan pertanyaan dikalangan sahabat nabi SAW. Ikrimah mengatakan, "Seseorang bertanya kepada Ibnu Abbas RA, "Apakah aku boleh makan limpa? Ibnu Abbas menjawab, "Iya". Laki-laki itu menjawab, "Sesungguhnya keseluruhan limpa itu darah". Ibnu Abbas menjawab, "Sesungguhnya yang diharamkan adalah darah yang mengalir". (Abu Bakar Ahmad bin al-Husain bin Ali al-Baihaqy, 1344H). Qatadah mengatakan, "Darah itu diharamkan selagi mengalir, adapun darah yang bercampur daging maka itu tidak apa-apa". Inilah sebabnya darah yang bercampur dengan daging dan air saat dimasak, tidak menjadikan daging itu najis dan haram. Dan inilah yang 
dilakukan Aisyah ra, bahwa ia masak daging dan masih nampak bekas-bekas darah pada rebusan dagingnya. Aisyah berkata, "Sesungguhnya Allah hanya melarang dari darah yang mengalir". (Abu Bakar Ahmad bin alHusain bin Ali al-Baihaqy, 1999). Yang dimaksud dengan darah yang mengalir adalah darah yang keluar dari hewan yang disembelih. Itulah darah yang berbahaya bagi kesehatan jika ditahan dalam tubuh. Ketika darah itu telah dikeluarkan dari dalam tubuh hewan ternak yang disembelih maka hilanglah bahayanya dan dagingnya baik untuk dikonsumsi. Dengan demikian sisa-sisa darah yang tertinggal dalam daging setelah hewan itu disembelih maka darah tersebut halal dan suci. (Abdurrahman Bin Nashir bin Abdullah as-Sa'dy, 2000).

Secara khusus Allah juga telah mentakhsis makna "ad-dam" dalam surat al-Maidah ayat 3 di atas dengan surat al-An'am ayat 145. "Katakanlah: "Tiadalah aku peroleh dalam wahyu yang diwahyukan kepadaku, sesuatu yang diharamkan bagi orang yang hendak memakannya, kecuali kalau makanan itu bangkai, atau darah yang mengalir atau daging babi...”. Qatadah mengatakan, "Kalau Allah tidak menurunkan ayat ini, niscaya manusia akan terus menelusuri darah sampai yang ada di dalam alirannya, sebagaimana orang Yahudi yang terus bertanya dan menelisik" (Adil Abdul Qadir Hamidah, 2009).

Bagaimana dengan kata “"وَلَحْمُ الْخِنْزِيرِ"? Berbeda dengan kata "al-maitah" dan "ad-dam" untuk kata khinzir secara khusus Allah menyebutkan kata "lahm" artinya daging. Apakah ini berarti yang haram dari babi itu hanya dagingnya saja? Inilah yang dipahami oleh Ahmad Subhi Manshur. Ia berpendapat bahwa keharaman babi itu terletak pada pengkonsumsiannya saja, tidak pada pemakaiannya yang lain. Artinya bisa saja babi itu digunakan untuk kegunaan yang lain bukan untuk dimakan misalnya untuk pasta gigi, industri kulit dan lainnya. (Ahmad Subhi Manshur, 2007).

Sementara para ulama klasik memahami bahwa yang haram dari babi itu bukan hanya memakannya saja, tapi haram secara mutlak. Haram memakannya, haram menggunakannya dan haram seluruh bagian tubuhnya; termasuk bulu, tulang dan lainnya. Terkait dengan hal ini Imam Fakhruddin arRazi mengatakan bahwa umat telah sepakat mengenai keharaman babi dan seluruh bagian tubuhnya. Allah SWT menyebutkan daging babi karena dagingnya banyak terpakai. (Fakhruddin ar-Razi, 2000). Imam alQurthubi juga berpendapat bahwa umat sepakat mengenai haramnya lemak babi. (Imam Abu Abdullah bin Ahmad bin Abu Bakar bin Farh al-Qurthuby, 1964). Demikian juga yang dikatakan Imam an-Nawawi dan lainnya. Sementara itu Imam Ibnu Hazm mengatakan bahwa sedikitpun tidak halal mengkonsumsi unsur babi; baik dagingnya, lemaknya, kulitnya, syarafnya, tulang rawannya, sumsumnya, otaknya, tulangnya, kepalanya, kukunya, susunya, rambutnya, jantan maupun betina, besar atau kecil semuanya sama." (Imam Ibnu Hazm azh-Zhahiri, 1352).

Lalu mengapa Allah tidak menyebut "wa alkhinzir" artinya "dan babi"? Jika Allah menginginkan keharaman babi itu secara mutlak, dagingnya, bulunya, ingusnya, tulangnya, tentu Allah seharusnya menyebutkan kata "khinzir" bukan "lahm al-khinzir". Hal ini dalam al-Qawaid al-Ushuliyah al-Lughawiyah dikenal dengan majaz mursal. Majaz mursal adalah kata yang dipakai bukan untuk makna aslinya, tapi karena adanya hubungan yang tidak mirip, yang disertai dengan isyarat atau qarinah (petunjuk) yang menghalanginya dari digunakan pada makna aslinya. Diantara bagian dari alaqatul majaz (hubungan majaz) ada al-juziyah (parsial), yaitu "dzikrul juz wa uriida bihil kull" (menyebutkan bagiannya sementara yang dimaksud adalah keseluruhan bagiannya). (Ali al-Jarim dan Mushthafa Amin, 2007).

\section{KESIMPULAN}

Betapa pentingnya memahami teks menggunakan analisis kebahasaan, karena tidak selamanya ayat atau teks-teks tersebut memiliki makna zhahir saja. Terkadang ia memiliki makna tersembunyi yang hanya bisa dijangkau dengan menggunakan analisis kebahasaan. Terkadang sebuah nash juga memiliki korelasi dengan nash-nash lain, baik itu dalam Al-Quran sendiri, antar ayat, atau dijelaskan maknanya dengan hadits. Jangan sampai seorang penggali hukum menganggap sebuah nash itu umum tapi ternyata sudah ditakhsis dengan nash lainnya atau sebaliknya. Atau bisa saja kita memahami perintah itu wajib ternyata sunah atau yang lain.

\section{DAFTAR PUSTAKA}

Silmy, 'Iyadh bin Namy As-, (2005), Ushul al-Fiqh alLadzi Laa Yasa'u al-Faqihu Jahluhu, Fakultas Syariah, Riyadh.

Hito, Muhammad Hasan, (2005), al-Khulashah Fi Ushul al-Fiqh, Dar Adh-Dhiya', Kuwait.

Sa'dy, Abdurrahman bin Nashir bin Abdullah As-, (2000), Taysir al-Karim ar-Rahman Fi Tafsir alKalam ar-Rahman, Muassasah Ar-Risalah, Beirut.

Suyuthi, Abdurrahman bin Abu Bakar As-, (2003) AdDurar al-Mantsur Fii at-Tafsir bi al-Ma'tsur, Dar Hijr, Mesir.

Hakim, Abu Abdillah al-, (2002), al-Mustadrak 'Ala ash-Shahihaini, Dar al-Kutub al-Ilmiah, Beirut.

Mubarakfury, Muhammad bin Abdurrahman bin Abdurrahim al-, (1990), Tahfat al-Ahwadzi, Dar al-Kutub al-Ilmiyah, Beirut. 
Baghawi, al-Husain bin Mas'ud al-, (1983), Syarh asSunnah, al-Maktab al-Islamiy, Beirut Damaskus.

Baihaqy, Abu Bakar Ahmad bin al-Husain bin Ali al-, (1344), as-Sunan al-Kubra, India.

Katsir, Abu al-Fida' Ismail bin Amr bin, (1999), Tafsir al-Quran al-Azhim, Dar Thayyibah. Kairo.

Sa'dy, Abdurrahman Bin Nashir bin Abdullah As-, (2000), Taysir al-Karim ar-Rahman Fi Tafsir alKalam ar-Rahman, Muassasah Ar-Risalah, Beirut.

Hamidah, Adil Abdul Qadir, (2009), Ensiklopedia Makanan dalam Islam dan Hukumnya Antara
Ilmu dan Iman, Penerbit Alamia, Alexandria Mesir.

Manshur, Ahmad Subhi, (2007), Apakah Lemak Babi itu Halal, (http://www.ahl-alquran.com)

Razi, Fakhruddin Ar-, (2000), Mafatih al-Ghaib, Dar al-Kutub al-Ilmiah, Beirut.

Qurthuby, Imam Abu Abdullah bin Ahmad bin Abu Bakar bin Farh al-, (1964), al-Jami' Li Ahkam al-Quran (Tafsir al-Qurthubi), Dar al-Kutub alMishriyah, Kairo.

Zhahiri, Imam Ibnu Hazm Azh-, (1352), al-Muhalla Bi al-Atsar, Dar al-Fikr, Beirut 